\title{
Challenges for Huawei to Go Global Under the Trade Disputes
}

\author{
Ziyang Peng ${ }^{1, * \dagger}$ Sihan Zhang ${ }^{2, *, \dagger}$ \\ ${ }^{1}$ Newcastle University, Newcastle upon Tyne, Tyne and Wear, United Kingdom \\ ${ }^{2}$ Hunan Industry University, Changsha, Hunan, China \\ *Corresponding author.Email: ${ }^{\text {*b }} 9065497 @$ newcastle.ac.uk, ${ }^{b} 1410784716 @ q q . c o m$ \\ These authors contributed equally.
}

\begin{abstract}
For the development history of Huawei, there are many reasons why it has developed from a small enterprise to its current scale, why Huawei can become the world's leading communications company in a short period. In recent years, facing the targeting problems and challenges from the United States, why Huawei can survive even though they have a certain impact. Where will Huawei go in the future? This paper uses some examples to comprehensively analyze Huawei from the inside to the outside aspects. The internal analysis is based on the company's high-level decision-making and Huawei's unique equity system; the external analysis is based on national policies and international disputes to analyze how Huawei develops. Since its development, Huawei has faced numerous opportunities and challenges. It seeks to develop through survival and builds its grand vision step by step in the development. This study will propose several points to expand and analyze Huawei's growth process.
\end{abstract}

Keywords: Huawei, Policy Support, Sanctions, Trade Disputes, Globalization

\section{INTRODUCTION}

In recent years, Huawei has obtained a series of achievements. According to public information on Huawei's official website: Huawei's contracted operators ranked No.1 in 5G network experience; Huawei's global terminal connections exceeded 1 billion, and the number of mobile phone users exceeded 730 million, the number of overseas applications in Huawei's application market has increased more than 10 times compared with the year of 2019, the HMS ecosystem has become the world's third-largest mobile application ecosystem, etc. This series of achievements confirm the evaluation of Huawei Business Administration Professor John Quelch from Harvard Business School. "Even among the very successful and international companies in China, Huawei is also a leader." Why can a rising star develop quickly, getting rid of many industry leaders like Ericsson and Nokia at the time, and become the mainstay of China's technology industry, competing with Apple Inc.? Perhaps as Zhengfei Ren said, "Huawei will have nothing left but management." For example, the emergence of Huawei's rotating CEO system has avoided the phenomenon of "one emperor and one courtier". Because of the good corporate governance mechanism, Huawei can survive and rank among the best in the current fierce competition.
Based on this starting point, this research on Huawei will adopt the method of case analysis and mainly focus on three aspects: one is the impact of national policies on Huawei's corporate governance; the second is how the board of directors 'decisions affect the development of Huawei; and the third is the factors affecting corporate governance by the external environment of the enterprise.

\section{LITERATURE REVIEW}

In developing to the present for several decades, Huawei has worked hard to overcome various problems and has developed into a world-leading communications company, which many experts and scholars have also studied. As early as 2007, the National Development and Reform Commission and the Ministry of Commerce proposed to give priority to the development of the digital mobile communications industry and the communications industry; in 2009, the Ministry of Industry and Information Technology of China also proposed to accelerate the construction of information network infrastructure. In the following years, China has been increasing its $R \& D$ investment in the communication equipment manufacturing industry in a policy-driven manner [1]. Because of the support of national policies, since the 1980 s, there has been a good 
growth environment within the industry, which has always promoted the development of Huawei. However, because of this, many innovative companies have entered this industry, and some companies with advanced technologies are actively engaged in business in China, and the competition is fierce [2]. In the early days of entrepreneurship, constant technology imitating was difficult to gain a foothold in the market. Huawei used low-end technology products to enter the rural market and realized the transformation from an agent to a manufacturer [3]. During the development period, the development of Huawei's internal environment becomes extremely important, and corporate governance becomes a very important part. Several different structural models have also emerged during the development of corporate governance. For example, the main characteristics of the American corporate governance structure model are decentralized equity and high liquidity, the governance structure is composed of the general meeting of shareholders and the board of directors with no board of supervisors, and the company adopts stock options to motivate managers [4]. Therefore, many Chinese companies continue to learn from foreign corporate governance mechanisms, to obtain scientific development of their companies. Huawei is no exception. After years of continuous changes in combination with its characteristics, Huawei has also owned a set of unique corporate governance mechanisms. After the development period, Huawei gradually moved towards the international market. Huawei chose the Hong Kong market as a breakthrough point, avoided weaknesses, and succeeded with a good service attitude, making it the first step towards the international market [5]. The rapid expansion of its overseas activities stems from three driving forces: the first driving force is the government's support. It is eager to explore cutting-edge technology from overseas to make up for the weak domestic industrial technology foundation. For example, China's "going out strategy" and the "Made in China 2025" plan. The second driving force comes from the company's high-intensity expansion of overseas markets and technological innovation pressure, learning and absorbing the advanced technology from counterparts in developed countries through overseas R\&D activities. The third driving force is the pressure of the financial environment. For example, the global financial crisis occurred in 2008. This financial crisis led to a crisis in the capital chain, especially in developed countries, which provided emerging market countries with a rare opportunity to purchase overseas technology assets. In addition, Huawei has invested a lot of money in technology research, and its invention patents account for $90 \%$ of its total patents. This has also become Huawei's core competitiveness [6]. Nowadays, the domestic smartphone market is in a stage of monopolistic competition, and the mobile phone market share is saturated [7]. Moreover, in terms of international business, various conflicts of interest have arisen in the face of different business models and political environments in Western economies. In particular, its operations have been plagued with sanctions by the United States and other Western countries. Therefore, Huawei's decision-making strategies have entered different directions. Not long ago, Huawei talked about discussing a digital transformation strategy with Huayi Group, building a "black earth" for business support and continuously improving customer experience [8]. Recently, new energy vehicles and autonomous driving technologies have developed rapidly, and the use of chips in automobiles has been increasing, which has a bright future [9]. Continuously broadening the business direction is the correct decision in the current fierce competition environment.

This paper analyzes the growth process of Huawei from both internal and external parts. Internal aspects include the support and impact of Chinese policies on Huawei and the promotion of Huawei's own unique internal mechanisms and unique management styles to Huawei's continuous development and progress. External aspects include the impact of international sanctions or friendly policies on Huawei and other domestic companies in overseas markets. In addition, it will also briefly describe the opportunities and challenges Huawei faces in terms of technology and market opening in conjunction with Huawei's innovative technologies.

\section{INTERNAL FACTORS}

\subsection{Support from domestic policy to the company}

\subsection{1 ."Two exemptions and three halves."}

China has enacted the "two exemptions and three halves" policy to encourage the development of domestic technology software enterprises, the fundamental purpose of which is to counteract the U.S. "entity list" policy. The "two exemptions and three halves reduction" refers to the preferential period calculated from the profit-making year before December 31, 2018, with the first to second years exempted from corporate income tax and the third to fifth years reduced by half at the statutory rate of $25 \%$ until the expiration of the period [10]. In addition, China's support for Huawei enterprises started early, and Huawei invests a large amount in R\&D every year. 80.7 billion RMB was invested in 2017 alone, and R\&D expenditure has reached 190 billion RMB in the last decade, making it into the top 10 non-military enterprises globally in terms of $R \& D$ expenditure. According to the new policy of R\&D expense deduction, Huawei can reduce tax or more than 3 billion yuan per year after implementing the new policy of R\&D expense deduction in 2018 [11]. National support policies, focusing on science and technology innovation, have focused on increasing enterprise $R \& D$ investment 
support. There is a growing demand for domestic substitution in the chip and software industry.

The United States on China's chip and semiconductor industry, high-pressure sanctions, this heavy tax reduction policy is developing domestic integrated circuit design and software and software industry enterprises to provide a lot of conveniences. The country's hand to support China's chips and software, tax breaks favorable to Huawei, Huawei such technology companies have important significance. Self-development of powerful "Chinese chip" is just around the corner. In addition, Huawei is aware that the United States is suppressing Huawei for political purposes. Founder Ren Zhengfei pointed out that the crackdown on Huawei in the United States is politically correct. The ultimate goal is to eliminate Huawei, to be prepared for the long-term existence of the list of entities. Therefore, Huawei adopted a completely different response strategy than when ZTE encountered the U.S. "entity list" in 2017: insist on principles, stick to the facts, no illusions, no compromise, and quickly start the "extreme survival" plan [12]. Zhengfei Ren stressed that the trade lawsuit between Huawei and the U.S. should be clarified with facts and evidence before discussing settlement. Otherwise, it would never admit guilt and reach a compromise settlement agreement. This clear understanding and decisive decision for the next Huawei to overcome the difficulties, calmly respond to the "entity list" suppression established an action guide.

\subsubsection{Integrated circuits}

In 2011, to encourage the development of the software industry and integrated circuit industry, the state issued a notice to encourage the development of the software industry and integrated circuit industry the number of policies [13]. After implementing the policy, the software industry and integrated circuit industry has expanded rapidly, rapid development, technology, and technology level significantly improved, to promote the national information construction. However, China's software industry and integrated circuit industry development foundation are relatively weak, enterprise science and technology innovation and self-development ability are not strong, application development level urgently needs to improve, the industrial chain to be improved, and other issues. The country has been slowly improving the problems arising from the policy. Later on 8 May 2019, Premier Li Keqiang hosted an executive meeting of the State Council. It was decided to extend the preferential income tax policy for integrated circuit and software enterprises to attract more domestic and foreign investment to participate and promote the development of the information industry. In addition, the State Council passed a resolution to extend policy preferences for the IC and software industry to encourage domestic and foreign companies to develop the IC and software industry through huge tax incentives [14]. In addition, the General Assembly decided to implement the "two exemptions and three reductions and a half" based on the "two exemptions and three reductions and a half" for IC production enterprises or projects under different conditions, and to continue to implement the 2011 "Notice of the State Council on the Issuance of Several Policies to Further Encourage the Development of the Software and IC Industries" for IC design and software enterprises. In addition, the preferential policy of "two exemptions and three reductions by half" for income tax as specified in the 2011 Circular of the State Council on Further Encouraging the Development of Software Industry and Integrated Circuit Industry [15] shall continue to be implemented for IC design and software enterprises.

The national implementation of the preferential policy on taxation reflects the policy to support the IC industry. After the continuation of the policy, enterprises enjoy tax concessions, which will reduce the cost of related enterprises from the research and development, design, and production links. Due to the sanctions imposed by the United States, Huawei's overseas research and development of chip technology have been hampered. This series of favourable support policies from the state has also solved Huawei's difficulties. Huawei announced that its chip company Heisi Semiconductor to enable the "backup plan". Huawei's head office in Shenzhen is now also making greater efforts to support the IC industry.

\subsection{Promote the management system of the company}

\subsubsection{Rotating board system}

The rotating board system was transformed from the rotating CEO system. Huawei started the rotating CEO system in 2012. The so-called rotating CEO system means that the rotating CEO under the board of directors' leadership is the highest executive head of the company, with the senior management team taking turns to sit as $\mathrm{CEO}$, and they focus on the strategy and system building of the company. The most important feature of this mechanism is that the top executive is not the decisionmaker for production and operations but the presiding officer for strategic planning and system building and is only responsible for a short period. This new top-level system has been questioned by several people, the most vocal rebuttal to the rotating CEO system being a commentary entitled "The Rotating CEO System is a False Proposition". Gao argues that the real relationship between the board and the CEO is a contractual one, not a leadership one. Therefore, whether it is a "rotating CEO system led by the board of directors" or a "CEO system led by the board of directors ", both are not valid [16]. Subsequently, in 2018 Huawei abandoned the CEO 
rotation system in favour of a rotating chairman system. All directors of Huawei must be elected based on a general meeting of shareholders, forming a board of directors, and all boards of directors elect independent directors as chairman. The general manager is selected and hired by the board of directors. In addition, the chairman of the board, who all directors elect, is not the leader of the other directors and officers and does not have overriding authority over the other directors and officers. The board of directors is not the chairman, who selects and authorises the general manager [17]. So, when the board chairman is unable to perform his or her duties, any other director can be elected to assume that role. This is arguably the basis on which a rotating chairmanship would work.

Huawei is well equipped to implement a rotating board of directors because its governance system is basically in line with international standards. The company clearly recognises the relationship between the board of directors and the managerial level. As the governance body for strategic decisions, the Board of Directors approves and determines the strategic decision proposals made by the managers through this meeting system. This directional and purposeful decision-making is stable. And taking into account the time, ability, and knowledge structure of each director, the rotating chairman system allows for better complementarity. It is thus more conducive to achieving scientific strategic decision-making. Under the rotating chairman system, the rotating chairman, who emerges after the change of the board of directors, is the supreme leader of the company during the period of duty, leading the board of directors and the standing board of directors of the company and participating in both strategic decisions and day-to-day management decisions. In this case, the rotating system is more conducive to the spirit of democracy, increasing the scientific nature of decisionmaking and filtering the risk of personal control and personal decision-making by the majority shareholder.

\subsubsection{Employee shareholding system}

The Employee Stock Ownership Plan is Huawei's plan to organically combine its employees' individual contributions with the company's long-term development, forming a long-term common struggle and sharing mechanism. Huawei's development into a multinational enterprise of technological innovation and the world's largest telecommunications equipment provider, and its high growth despite the US blockade, is largely due to its core values and corporate culture of "customer-centric, strivers-oriented, and long-term hard work", as well as the governance mechanism and management system formed on this basis [18]. Huawei was founded in 1987 in Shenzhen, and the company's early shareholding was an employee shareholding plan that continues to this day. $100 \%$ of Huawei's shares are held by employees, of which $10.05 \%$ are held by retired and business restructuring employees, Zhengfei Ren holds $1.01 \%$, and $88.94 \%$ are held by current employees [19]. An important feature of Huawei's governance mechanism is that all shares are in the hands of employees, the board of directors is staff-elected representatives, and employees control the company's direction. It can be said that employees are the company's true owners, fully embodying the basic characteristics of democratization.

Under the employee shareholding system, Huawei no longer seeks to maximize shareholder profits. This governance mechanism is fundamentally different from a modern enterprise system that seeks to maximize shareholder profits under the conditions of separation of ownership and management rights. Huawei has long insisted that employees hold $100 \%$ of its shares. This ownership structure is the basis for Huawei's democratization of incentives and is crucial to Huawei's success. As owners of the company, employees run it with the attitude of their own company, so they do not focus only on immediate benefits but also on the future development of the company. According to Zhengfei Ren, "This is one of the reasons why Huawei has been able to catch up with its peers in the industry. Huawei's employees are also the owners of the company, so they tend to look at the long term and are not eager to cash out"[20]. The corporate culture has highlighted the importance of employees' interests rather than being constrained by capital. The main reason for this is that employees are also the company owners, and they will be more long-term oriented and willing to continuously increase the company's investment in research and development. In addition, Huawei has developed a workbased distribution model over a long period to fully motivate employees. Ren Zhengfei believes: "How to make employees do their best? The key is to establish a fair value evaluation and value distribution system so that employees form a reasonable expectation that you will give them a reasonable return after they have done their best. And how to make value evaluation fair? It is to implement the principle of equal contribution and equal pay so that everyone's motivation is mobilized" [21]. Huawei's work-based distribution model is reflected in the implementation of a functional salary system based on competence in salary distribution; the distribution of bonuses linked to departmental and individual performance improvements; the distribution of benefits such as safety pensions, based on the results of work attitude appraisals; and health insurance differential treatment between senior management and senior professionals and general employees according to their contribution. It should be said that it is very difficult to measure the work results of employees in different positions fairly and impartially. That one can only pursue as much fairness and impartiality as possible while ensuring equal opportunities. Huawei's work-based 
distribution model embodies democracy in the way it is distributed. This democratization system has continued to the present day and is why Huawei has resisted many crises and is still standing.

\section{EXTERNAL FACTORS INFLUENCE}

\subsection{Policy containment in developed countries}

\subsubsection{The negative impact of the "Entity List" issued by the United States on Huawei}

In May 2019, the US put Huawei and many of its subsidiaries on the "Entity List", requiring US companies to obtain US government approval before exporting parts and technology to Huawei. The "entity list" system is a comprehensive approach to suppressing Huawei through market restrictions, technology blockades, industry chain disruptions, and reputational slander, which has dealt a severe blow to the company [22]. The growing conflict between the US and China has put both their economic and diplomatic relations at risk. After escalating the trade war through tariff hikes, the US began to restrict Huawei's cooperation with US companies. As the trade war expands into a "technological cold war", the chances of an agreement between the two sides appear to be diminishing. The recent US action against Huawei is a watershed moment, and tensions have escalated," said Michael Herson, head of Asia at Eurasia Group [23]. The repression of Huawei has become central to Washington's relationship with Beijing. US Commerce Secretary Wilbur Ross has pointed out that Huawei and its foreign affiliates have evaded the US entity list restrictions by various means. He stated that the US must fix the regulations that Huawei and Heisi have exploited to prevent US technology from contributing to malicious acts that strike US national security and foreign policy interests [24]. The US justifies its action against Huawei by claiming that it poses a risk to national security. The US claims to protect the country's security. The US government believes that Beijing could use Huawei's equipment for espionage, a claim that Huawei has consistently denied. The "entity list" sanctions imposed by the US have hit Huawei hard, with the biggest problem being the cut-off of Google's supply. Huawei's mobile phones cannot use Google's Android-based software.

The impact of the US "entity list" policy on the industry has been swift. TSMC, Intel, Qualcomm, MediaTek, Micron, and other chip companies have announced that they will not continue supplying chips to Huawei after September 15. Even China's chip foundry, SMIC, has politely stated that it will "absolutely comply with international regulations". However, these companies have also indicated that they have submitted separate applications to the US to obtain temporary permission to continue supplying Huawei [25]. Many are skeptical of the US' willingness to reduce policy sanctions due to its previous inconsistent policies. Previously, Huawei's 5G technology and hightechnology technologies such as the Hysis chip have seriously affected the dominance of the US in the field of core technologies. At the 2020 Summit of the China Informatization 100, Huawei's consumer business CEO Chengdong $\mathrm{Yu}$ said Huawei would release a new generation of the flagship phone, the Mate 40, with Huawei's own developed Kirin 9000 chip. Still, due to the US sanctions, the chip was not produced and is currently all out of stock, which could be an extinct version of Kirin's high-end chip[25]. This is a huge bump for Huawei, which was banking on $5 \mathrm{G}$ chip technology to break through the modern technological status quo to become a more powerful technology company. Still, this sanction policy has hindered the company's future overseas market development and technological development. Huawei will have to rely on national policies for subsidies and its own internal hiring of highend technical staff.

\subsubsection{Other influences of the $E U$}

The US has repeatedly pursued a policy of suppression against Huawei, leading to a marked change in the mobile network market supplier landscape for global operators. When the fifth generation of mobile internet was launched, the US and Australia were very concerned about cybersecurity for Huawei's outgoing handsets. Subsequently, they banned Huawei from participating in the push. Although Huawei first proposed $5 \mathrm{G}$, leading the market and currently playing a role in $4 \mathrm{G}$ networks, its fate in the EU market is in jeopardy [26]. EU countries are concerned about Huawei's ability to deliver and follow up maintenance afterward. Many operators have chosen to abandon Huawei in favor of other equipment vendors such as Ericsson and Nokia. Huawei has been forced to replace many contracts in the European region and the Americas. According to public information compiled by Light Reading (table1)[27], in Europe, operators in at least a number of countries, including the UK, Germany, Denmark, and Norway, have abandoned their original contracts with Huawei in favor of Ericsson or Nokia. The same thing is happening in countries in the Americas, such as Canada and Argentina. Looking at the table, Huawei has become a big loser. Nokia is not doing well, and only Ericsson has laughed off almost all the contracts lost by Huawei and has become the biggest winner. 
Table.1 Mobile network deals entailing vendor changes

\begin{tabular}{|c|c|c|c|c|c|c|}
\hline Operator & Country & Date & New vendor & $\begin{array}{c}\text { Original } \\
\text { vendor }\end{array}$ & Domain & Details \\
\hline Vodafone & UK & Jun-17 & Ericsson & Nokia & RAN & $\begin{array}{c}\text { Swedes usurp } \\
\text { Finns in } \\
\text { Vodafone's } \\
\text { London Network }\end{array}$ \\
\hline $\begin{array}{l}\text { Deutsche } \\
\text { Telekom }\end{array}$ & Germany & Dec-17 & Ericsson & Huawei & RAN & $\begin{array}{l}\text { Nokia ditched in } \\
\text { favor of Ericsson } \\
\text { in Geman RAN }\end{array}$ \\
\hline Telefonica & Argentia & Jun-17 & Ericsson & Huawei & RAN & $\begin{array}{l}\text { Ericsson grows } \\
\text { market share at } \\
\text { Huawei's expense }\end{array}$ \\
\hline TDC & Denmark & Mar-19 & Ericsson & Huawei & RAN & $\begin{array}{l}\text { Swedish vendor to } \\
\text { replace Huawei as } \\
\text { TDC rolls out 5G }\end{array}$ \\
\hline Telia & Norway & Aug-19 & Ericsson & Huawei & RAN & $\begin{array}{c}\text { As sole RAN } \\
\text { Vendor, Ericsson } \\
\text { will replace } \\
\text { Huawei by } 2023\end{array}$ \\
\hline KPN & Netherlands & Nov-19 & Huawei & Ericsson & RAN & $\begin{array}{l}\text { Huawei phasing } \\
\text { Ericsson out of } 4 \mathrm{G} \\
\text { as it builds } 5 \mathrm{G} \\
\text { network }\end{array}$ \\
\hline BT & UK & Apr-20 & Ericsson & Huawei & Core & $\begin{array}{l}\text { Ericsson will } \\
\text { replace Huawei in } \\
\text { BT's core by } 2023\end{array}$ \\
\hline Telus & Canada & Jun-20 & $\begin{array}{c}\text { Ericsson, } \\
\text { Nokia }\end{array}$ & Huawei & RAN & $\begin{array}{c}\text { Nordic vendors } \\
\text { but not Huawei } \\
\text { named as 5G } \\
\text { suppliers }\end{array}$ \\
\hline $\mathrm{BCE}$ & Canada & Jun-20 & Ericsson & Huawei & RAN & $\begin{array}{l}\text { Ericsson but not } \\
\text { Huawei named as } \\
\text { 5G supplier }\end{array}$ \\
\hline Telefonica & Germany & Jun-20 & Ericsson & Huawei & Core & $\begin{array}{l}\text { Chinese vendor } \\
\text { ejected from core } \\
\text { in favor of } \\
\text { Ericsson }\end{array}$ \\
\hline
\end{tabular}

In addition, according to data published by market researcher Canalys (table2) [28], Samsung, Huawei and Apple ranked among the top three in the European smartphone market. Still, all three mobile phone companies saw a decline in shipments in the European market, with their declines of $23 \%, 35 \%$, and $10 \%$, respectively. But in the first quarter of 2020, Huawei's mobile phone shipments in the European market plummeted 35\% year-on-year, the highest drop among the top five mobile phone companies, and Huawei's route gradually became apparent. On September 15, 2020, the
US ban on Huawei came into effect, and Huawei then faced a "dark moment" of "core breakage". Huawei finally agreed to sell its subsidiary, Honor [29]. Huawei gradually receded from its original peak.

Table 2. Europe: Top smartphone vendors, Q1 2020

\begin{tabular}{cccc}
\hline & Vendor & United share & YoY Growth \\
\hline 1 & Samsung & $33 \%$ & $-23 \%$ \\
2 & Huawei & $21 \%$ & $-35 \%$ \\
\hline
\end{tabular}




\begin{tabular}{lccc}
\hline 3 & Apple & $18 \%$ & $-10 \%$ \\
4 & Xiaomi & $14 \%$ & $+58 \%$ \\
5 & Oppo & $2 \%$ & $+1014 \%$ \\
\hline
\end{tabular}

\subsection{One Belt and One Road Policy}

"One Belt, One Road" policy is a good policy for enterprises to develop overseas and to increase the country's international influence. On 12 June 2019, Minister Hui Ma attended and spoke at the "One Belt, One Road" and the Future of the World seminar organized by the Chinese Business Institute at the Judge Business School, University of Cambridge. On 12 June 2019, Minister Hui Ma attended and spoke at a seminar on "One Belt, One Road" and the future of the world organized by the Jaki Business School at the University of Cambridge, where many students learned about the benefits of the "One Belt, One Road" [30].

Countries on the "One Belt and One Road" line are all taking a step forward, and Chinese enterprises are also developing outward through this Silk Road. In the G20 summit, we discussed the Chinese economy and Chinese enterprises in the innovative development and breakthrough in supply-side structural reform. Zhang Yansheng, secretary-general of the Academic Committee of the National Development and Reform Commission and former director of the Institute of Foreign Economic Studies of the National Development and Reform Commission, said at the meeting that there would be no Huawei without One Belt and One Road. Still, in turn, Huawei also benefits from One Belt and One Road. Yansheng Zhang said $70 \%$ of Huawei sales are overseas. Huawei sales start from Asia, Africa, and Latin America, the poorest places in Africa, India, and the world. Huawei drives the mutual development of countries to support each other. Huawei, as the leader of China's private enterprises, the construction of "One Belt and One Road" on communication facilities will bring new development space to Huawei. Huawei in the "One Belt and One Road" opportunity is naturally extraordinary results. Since the implementation of Huawei's internationalization strategy in 1996, according to the changes, the environment and international needs to learn, adjust and accumulate "spontaneous experience", but also at a huge expense of introducing international advanced management experience, and combined with local management practice, has made brave exploration, made great achievements, and become a rare precious wealth in China's corporate community. Huawei's international experience, with small, maybe "One Belt and One Road" to learn from.

\section{OPPORTUNITIES AND CHALLENGES}

\subsection{Harmony OS}

Because the US Department of Commerce announced that Huawei and its 70 related affiliates were included in the "entity list" for export control, then in 2019, the Harmony OS independently developed by Huawei attracted public attention. Harmony OS is a "futureoriented" operating system that can be adapted to various terminal devices such as smart cars, TVs, mobile phones, tablets, etc. Harmony OS is a backup solution developed by Huawei for more than ten years, just to take precautions [31].

Recently, Huawei announced that it planned to formally hold the Harmony OS products launch conference on June 2. At the same time, it would release the startup screen video of the Harmony OS mobile phone operating system on Huawei's official Weibo "Harmony OS". Huawei said the company's Harmony OS would be officially released to the world soon. The Harmony OS is technically geared to IoT devices with high requirements for delay and reliability but low energy consumption requirements. Therefore, Harmony OS has more advantages in industry, aviation, aerospace, and machine tool automation [32]. In terms of competition, Android and IOS are undoubtedly the two strongest competitors. However, IOS has always been dissatisfied by many consumers and developers because of the "Apple tax,"; and the fragmentation problem of Android has not been solved, which has brought a bad experience to many consumers. As a brand-new system, Harmony OS must have certain advantages in these two aspects. However, Android and Apple have been developing for a long time and cover a wide area. It is difficult to stand out in a deeply rooted environment. It is understood that on May 19, Google held a developer conference and officially released the Android12 system. Many domestic manufacturers updated the original sound pack of Android12 for the first time. However, Huawei is not on the Android adaptation list, which means Huawei was officially "delisted" by Google [33]. Nowadays, Android, IOS, PC-side Windows, etc., have established a rich ecosystem in their respective fields and have a very solid moat. As a rising star, Huawei's Harmony OS has long lost its first opportunity. If it wants to build a completely isolated ecosystem like others is not realistic. So, opening source communities and coexistence are the only way to go. This also means that the road for Huawei Harmony OS to enter the domestic and even international markets is very tortuous. However, now that $5 \mathrm{G}$ may bring new points of change, a good launch time will also become a good development opportunity. Obviously, Huawei's Harmony OS has a long way to go. 


\subsection{Autonomous Driving}

With the maturity of blockchain technologies, competition in the intelligent driving car industry is intense. According to Deloitte's forecast, China will have 30 million autonomous vehicles in operation by 2030, ranking first globally. Because of this, many giant industries want to get a share of this industry. Baidu teams up with Baixin Bank to create a new model of smart car banking; Xiaomi bets on all its savings to build smart cars; Alibaba works with SAIC Group to build "smart cars"; Tencent, together with Geely, develops automatic cockpits and autonomous driving [34].

In 2021, before the Shanghai International Auto Show, Huawei and BAIC Blue Valley jointly created the Alpha S Huawei HI version, which was successfully launched and attracted the attention of many people in the market [35]. This car is equipped with Huawei's autonomous driving technology. Its visual recognition system is applied lidar recognition technology with the highest safety factor. According to the definition of the autonomous driving capability of the American Society of Automotive Engineers, the autonomous driving technology of Polar Fox Alpha S has reached the L4 level. Huawei's action is "absolutely No. 1" in auto BU ranking. According to Su Qing's opinion, the President of Huawei's intelligent driving, Huawei has more than 2,000 people in the team of the field of autonomous driving, with an investment of about 1 billion US dollars a year. It is expected to maintain an annual growth rate of about $30 \%$ in the future [36]. With a large amount of capital investment and core technology mastery every year, Huawei has an absolute competitive advantage. Wang Jun said that Huawei not only got technological innovations but also got innovations in business models. Huawei does not build cars and only provides technology, while automakers provide the strength of vehicle manufacturing and jointly develop high-quality models. In cars with Huawei solutions, in addition to the manufacturer's logo, the Huawei HI logo will also be added [37]. Huawei does not consider the issue of shortterm profitability. It is always taking a long-term route. It wants to build an ecosystem in the automotive industry, and technology is the basis for getting out of the circle.

\subsection{Huawei Cloud}

Up to now, Huawei Cloud has been established for about 4 years, but its growth rate is amazing. Not only has it created the fastest growing record for a cloud computing "big factory", but its market share has surpassed Tencent Cloud, second only to Alibaba Cloud, and rushed to China's top 2. Although Huawei Cloud started very late, its advantage is that it has won in technology. According to data from the German patent data company IPlystica, among the top ten companies with the most cloud computing patents globally, only Huawei of China is on the list, ranking the eighth [38].

In fact, since the development of cloud computing, Huawei Cloud has experienced many ups and downs. From the perspective of Huawei's internal strategy, the early start of cloud computing and AI business will conflict with Huawei's revenue from selling servers and system solutions. The internal consumption problem of Huawei's Could\&AI and BEG businesses has not been resolved. It wasn't until 2020, when Ren Zhengfei required Huawei Cloud to become the "black land" of global enterprises, that Huawei Cloud's strategic position was clarified [39]. Since 2019, the United States has included Huawei in the "Entity List." Huawei has made frequent adjustments to Huawei Cloud, abolishing cloud and computing BG and dividing BG's business into two. $\mathrm{Xu}$ Zhijun said that the frequent adjustments of Huawei Cloud are to continuously improve software capabilities, return to software, and increase the proportion of software and service revenue [40]. In the face of US sanctions, Huawei's keyword in recent years has been to survive better. On May 17, at the Ecological Conference of Huawei Cloud's "Partners in the Same Boat 2021", iSoftStone became the strategic partner of Huawei Cloud for the second time from 2017. This year is a year of changing times. Facing the stage of digital transformation, more and more complex and diverse customer needs, and also faced with three problems: information islands, external ecological coordination, and lack of efficient data operation capabilities. The cooperation between Huawei and iSoftStone can help Huawei Cloud open up the market and become bigger and stronger, which is undoubtedly mutually beneficial. Huawei Cloud still faces many challenges. From covering the domestic market to slowly opening up the international market, there are still many ways to go.

\section{CONCLUSION}

Huawei's development in the international market will always be affected by domestic conditions and foreign trade disputes. The United States sanctions Huawei's international development, Huawei's development in the European market is not smooth, facing competition with many companies. National policies, Huawei's internal business model, and the company itself allow Huawei to ease and grow in the face of international environmental disputes. After a slow start in the development process, Huawei can now stand firm internationally and compete with other technology companies. The state and Huawei are supporting each other for two-way development. 


\section{REFERENCES}

[1] Chen,Xiaoling.Research on the Evolution of Huawei's Business Model-Based on the Business Model Canvas Model [D]. Jinan University, June 29, 2020: 1-57.

[2] Lou,Hangjia. Research on the Optimization of the Internal Environment of Chinese EnterprisesBased on the Case of Huawei's Transformation [D]. Zhejiang Gongshang University, January 2020: 184.

[3] Yu,Dengke,\& Yan,Hongling. The Growth path of the Dual Coupling of Technological Innovation and Business Model Innovation: Study on the Development History of Huawei in the Past 30 Years[J]. Science and Technology Progress and Countermeasures, 2019, (23): 85-94.

[4] Yu,Han. Research on Optimization of Corporate Governance Structure of Changtuo Group [D]. Jilin University, May 2012: 1-52.

[5] Yang,Lei.An Analysis of the Internationalization of How to Grow into a World-class Multinational Company-Taking Huawei as an Example[J]. Popular Business, 2021, (04): 7-8.

[6] Han, Siwei. Analysis of the Core Competitiveness of Enterprises-Taking Huawei as an Example[J]. Guangxi Quality Supervision News, 2021, (04): 127-129.

[7] Kang,Maohua \& Wen,Xuehua. A Brief Global Market Research on Huawei $5 \mathrm{G}[\mathrm{J}]$. Frontiers in Economics and Management, 2021, (02): 187-194.

[8] Dai,Yongming. Huayi Group and Huawei jointly discuss digital transformation[J]. Shanghai Chemical Industry, 2021, (02): 72.

[9]An, Qingheng. How to Promote the Development of China's Automotive Chip Industry in the Era of Big Computing[J]. Automotive Aspects, 2021, (04): 6567.

[10] Sohu.com. Two free and three halves! After the Huawei incident, the Ministry of Finance and the State Administration of Taxation once again supported Create China [EB/OL]. https://www.sohu.com/a/315855200_723084.

Accessed on May 12, 2021.

[11] Sohu. The state shot! Finance Department: Twoyear Tax Exemption for Chip and Software Companies [EB/OL].https://www.sohu.com/a/316 3102 34_169779. Accessed on May 12, 2021.

[12] Liu,Shuxing. An Exploration of National Security Trade Barriers Based on Game Theory Perspective
[J], Journal of Lanzhou University of Finance and Economics, 2020, (36): 41-50.

[13] The Central government network of the People's Republic of China. Notice of the State Council on the Issuance of Several Policies to Further Encourage the Development of the Software Industry and the Integrated Circuit Industry [EB/OL], http://www.gov.cn/zhengce/content/ 2011-02/09/content_3378.htm. Accessed 26 May 2021.

[14] The Central Government of the People's Republic of China. Continuation of the original preferential treatment for domestic and foreign enterprises Experts explain the preferential tax policies for IC and software enterprises [EB/OL]. http://www.gov.cn/zhengce/2019-05/09/ content_ 5390000. htm. Accessed 15 April , 2021.

[15] The Central Government of the People's Republic of China. Li Keqiang presides over State Council executive meeting, ministers to promote innovation and upgrading of state-level economic and technological development zones, etc. [EB/OL]. http://www.gov.cn/premier/2019.

05/08/content_5389764.htm. Accessed April 15, 2021.

[16] Gao, Minghua. The rotating CEO system is a false proposition[J]; Board of Directors; 2012, Issue 06

[17] Huawei Board of Directors. Who owns and controls Huawei? https://www.huawei.com/m inisite/whoruns-huaw ei/cn /. Accessed 15 April 2021

[18] Wang, Yiming. How Huawei built a democratized governance mechanism[J], People' s Forum, 2019, (34): $16-18$

[19] Huawei : Shareholding and Governance. Who owns and controls Huawei? https://www.huawei.com/m inisite/who-runs-huaw ei/cn /. Accessed 15 April , 2021

[20] Zhou,Xibing. Huawei Methodology (Striver-based) [M]. China Publishing Group: Modern Publishing House. 2018: 1-283.

[21] Xing, Ye. Made for a connected world: the business management wisdom of Ren Zhengfei [M]. Zhejiang People's Publishing House. 2018: 1-230.

[22] Liu, Shuxin. An Analysis of National Security Barriers to Trade: A Case Study of Huawei's Inclusion in the U.S. "Entity List" $[\mathrm{J}]$, Financial Development Review, 2020, (3): 1-25

[23] Kosta,A.N. How the Huawei case could harm two major global economies [EB/OL]. 
https://www.bbc.com/ zhongwen/simp/chinesenews-48458770. Accessed 12 April , 2021.

[24] Huawei dispute: US escalates export restrictions on Huawei

[EB/OL]. https://www.bbc.com/zhongwen/simp/ world52686916. Accessed 12 April, 2021.

[25] Huawei: China's telecom giant survives after 'core break' as toughest US ban takes effect [EB/OL]. https://www.bbc. com /zhongwen/simp/business54151243. Accessed 12 April, 2021.

[26] Mlexmarketinsight.com. Huawei's EU obstacles stem from regulatory uncertainty back home. [online] Available at: <https://mlexmarketinsight.com/news-hub/editorspicks/area-of-expertise/data-privacy-andsecurity/huaweis-eu-obstacles-stem-fromregulatory-uncertainty-back-home> [Accessed 10 June 2021].

[27] Companies, Newswires, light reading

[28] Canalys estimates (sell-in shipments),Smartphone, Analysis,May 2020

[29] Huawei sells its mobile phone sub-brand "Honor" to start the road to survival?[EB/OL]. https://www.BBC. com/zhongwen/ simp/business55014643. Accessed April 12, 2021.

[30] Embassy of the People's Republic of China in the United Kingdom of Great Britain and Northern Ireland. Minister Hui Ma attends Cambridge University seminar on "One Belt, One Road" and the Future of the World [EB/OL]. https://www.fmprc.gov.cn/ce/ceuk/chn/sgxw/2019s higuanhuodong /t1672548.htm . Accessed 20 April 2021.

[31] Fan, Zhongyi. Plan ahead to Win the Future [J]. Success and Employment, 2019, (10): 22-23.

[32] Liu, Yuanju. The "Big Test" of Harmony OS in the International Market [J]. Science Grand View Garden, 2019, (17): 61

[33] Sohu.com. The high-profile Announcement as been Splashed with "Cold Water" for Several Times. Is there any Market Opportunity for Huawei Harmony OS?

[EB/OL]. https://www.sohu.com/a/468700213_120446035. Accessed on May 29, 2021.

[34] Hong, Yan. Smart Car "Gluttonous Feast" Gushing out and Giants are "Grabbing the Beach" [J]. Business Forum, 2021 (05): 14-17.

[35] Han, Zhongnan. Why does Huawei, which "does not build cars", Make a Huge Wave in the Car Circle? [N]. Securities Times, 2021-4-20 (07).
[36] Wang, Xuanxuan \& Chen, Ruiya. The Elephant Enters the Game, and the Autonomous Driving Starts the "Infinite Game" [J]. Chinese Entrepreneur, 2021(05): 48-55.

[37] Gao, Chi. Huawei's Ambition: Put Smart Solutions into Every Car $[\mathrm{J}]$. Automobiles and Accessories, 2020 (21): 64-65.

[38] Sun, Bing. Huawei Has No Money, can't Learn from Alibaba? Huawei Cloud Rushed to the top 2 in China, but Ren Zhengfei Stepped on the Brakes[J]. China Economic Weekly, 2021(01): 53-55.

[39] Yang, Xiaohe. Why did Huawei Choose Yu Chengdong in the Historical Turning Point? $[\mathrm{J}]$. Enterprise Observation Room, 2021(01): 32-34.

[40] Dang, Bowen. What did the Huawei Analyst Conference analyze? [N]. Communication Industry News Central Level, 2021-4-19 (013). 